\title{
Transurethral resection of fibrotic scar tissue combined with temporary urethral stent placement for patients with in anterior urethral stricture
}

Cheol Yong Yoon, Ji Yun Chae, Jong Wook Kim, Jin Wook Kim, Mi Mi Oh, Hong Seok Park, Du Geon Moon, Jun Cheon, Jeong Gu Lee, Jae Jong Kim

Department of Urology and Center of Regenerative Medicine, College of Medicine, Korea University, Seoul, Korea

\section{ABSTRACT}

Introduction: Fibrotic scar formation is a main cause of recurrent urethral stricture after initial management with direct vision internal urethrotomy (DVIU). In the present study, we devised a new technique of combined the transurethral resection of fibrotic scar tissue and temporary urethral stenting, using a thermo-expandable urethral stent (Memokath ${ }^{\mathrm{TM}}$ 044TW) in patients with anterior urethral stricture.

Materials and Methods: As a furst step, multiple incisions were made around stricture site with cold-cutting knife and Collins knife electrode to release a stricture band. Fibrotic tissue was then resected with a 13Fr pediatric resectoscope before deployment of a Memokath ${ }^{\mathrm{TM}} 044 \mathrm{TW}$ stent $(40-60 \mathrm{~mm})$ on a pre-mounted sheath using $0^{\circ}$ cystoscopy. Stents were removed within 12 months after initial placement.

Results: We performed this technique on 11 consecutive patients with initial $(n=4)$ and recurrent $(n=7)$ anterior urethral stricture (April 2009 - February 2013). At 18.9 months of mean follow-up (12-34 months), mean $Q_{\max }(7.8 \pm 3.9 \mathrm{ml} / \mathrm{sec}$ vs 16.8 $\pm 4.8 \mathrm{ml} / \mathrm{sec}, \mathrm{p}<0.001$ ), IPSS (20.7 vs $12.5, \mathrm{p}=0.001$ ), and QoL score (4.7 vs $2.2, \mathrm{p}<0.001$ ) were significantly improved. There were no significant procedure-related complications except two cases of tissue ingrowth at the edge of stent, which were amenable by transurethral resection. In 7 patients, an average 1.4 times (1-5 times) of palliative urethral dilatation was carried out and no patients underwent open surgical urethroplasty during the follow-up period.

Conclusion: Combined transurethral resection and temporary urethral stenting is a effective therapeutic option for anterior urethral stricture. Further investigations to determine the long-term effects, and safety profile of this new technique are warranted.

\section{ARTICLE INFO}

Available at: www.brazjurol.com.br/videos/july_august_2014/Yoon_576_577video.htm

Int Braz J Urol. 2014; 40 (Video \#11): 576-7

Submitted for publication:

May 10, 2014

Accepted after revision:

July 15, 2014
Correspondence address:

Du Geon Moon, MD, PhD

Department of Urology,

College of Medicine, Korea University,

Guro Hospital,

148 Guro-dong, Guro-gu, Seoul, 152-703, Korea

Fax: + 822 2626-1321

E-mail: yoonyong@korea.ac.kr 


\section{EDITORIAL COMMENT}

The video by Yoon et al. demonstrates transurethral resection of an anterior urethral stricture combined with long term urethral stent placement. The small caliber of modern pediatric equipment facilitates transurethral resection of stricture tissue. In 2013 Jang and associates presented a series of patients treated with transurethral resection. In their series a Foley catheter was left in place for one week (1).

In both series a significant number of patients required postoperative dilations. In this most recent study 64\% (7/11) required post stent dila-

\section{REFERENCES}

1. Jang WS, Jeong SH, Yu HS, Hwang IS, Hwang EC, Kim SO, et al.: Initial experience of transurethral resection with pediatric resectoscope for incomplete anterior urethral stricture. Int Braz J Urol. 2013; 39: 295; discussion 296.

2. Jordan GH, Schlossberg SM: Surgery of the penis and urethra. In: Wein AJ, et al, (ed.), Campbell-Walsh Urology. Vol 1. 9th ed. Philadelphia, Pa: WB Saunders Co; 2007; pp. 1023-97. tions, presumably for return of obstructive symptoms. 36\% (4/11) required multiple dilations. Two patients required repeat transurethral resection for recurrent stricture despite an indwelling stent.

For patients with short strictures, excision with primary anastomosis remains the gold standard against which other techniques should be compared (2). It has proven to be a highly successful surgery and its results durable over time (3).

Additional patients and longer term data may help identify a subset of patients who can be treated effectively with transurethral excision. A randomized study may help to determine the exact benefits of longer-term temporary stenting.

3. Mundy AR: Management of urethral strictures. Postgrad Med J. 2006; 82(970):489-93

Hubert Swana, MD Pediatric Urology Nemours Children's Hospital Orlando Orlando, FL, USA E-mail: hswana@nemours.org 